\title{
BLAST LUNG INJURY: OUR EXPERIENCE AT A TERTIARY CARE MILITARY HOSPITAL
}

\author{
Ahmed Mujadid Burki, Saira Mahboob* \\ Combined Military Hospital/National University of Medical Sciences (NUMS) Rawalpindi Pakistan, *Combined Military Hospital Okara/National University of \\ Medical Sciences (NUMS) Pakistan
}

\section{ABSTRACT}

Objective: To study the management and mortality in patients with blast lung injury at a tertiary care military hospital. Study Design: Prospective, observational study.

Place and Duration of Study: Intensive Care Unit, Combined Military Hospital, Peshawar, from Jan 2013 to Dec 2014.

Methodology: After approval from Hospital Ethics Committee, 38 patients diagnosed with blast lung injury who were admitted to intensive care unit were included in our study.

Results: The mean age was $29.68 \pm 4.3$ years and all the patients were male. The incidence of blast lung injury in trauma patients was $38(10.2 \%)$. Most of the patients $18(47.4 \%)$ had severe ARDS due to blast wave and most of the patients 28 $(73.6 \%)$ required mechanical ventilation with lung protective strategy. The mortality in patients diagnosed with blast lung injury was $2(5.2 \%)$.

Conclusion: Blast lung injury is a common complication in survivors of bomb blast. As military doctors who treat both armed forces as well civilian casualties from blast injuries; the physician treating blast injury should be conscious of risk of patient developing blast lung injury; so that early recognition and prompt management with lung protective strategy can prevent increased morbidity and mortality.

Keywords: Blast lung injury, Mortality, Mechanical ventilation, Non-invasive ventilation.

This is an Open Access article distributed under the terms of the Creative Commons Attribution License (http://creativecommons.org/licenses/by/4.0), which permits unrestricted use, distribution, and reproduction in any medium, provided the original work is properly cited.

\section{INTRODUCTION}

Pakistan is fighting a war against terror for the last 20 years. The global mortality has been reported to be 34,676 deaths due to terrorism alone, accounting for $0.06 \%$ of deaths internationally for the year 2016 alone ${ }^{1}$. There have been 607 reported terrorism incidents in Pakistan since 2001. The estimated deaths from various terrorist activities is more than 16000; with more than 5000 shahadat of military personnel ${ }^{2}$. The military forces as well civilians have been targeted in terrorist bomb blasts. In addition, military forces are exposed to improvised explosive devices (IED) and firearm injuries. The explosive force from a blast can cause life threatening injuries causing multisystem involvement resulting in immediate or delayed mortality as well as increased morbidity. Most of the immediate mortality results from head injury, chest or lower limb trauma ${ }^{3}$. Blast injuries can be classified into four major groups. The primary injuries are due to the effect of the transmitted overpressure blast wave on gas containing organs; secondary injuries are due to impact of airborne debris; tertiary injury is due to transposition of the victims body because of blast wind or structure collapse; and quarternary injury encompasses injuries caused by the explosion 4 .

Correspondence: Dr Saira Mahboob, Graded Anesthetist, Combined Military Hospital Okara Pakistan

Received: 09 Mar 2019; revised received: 01 Oct 2019; accepted: 04 Oct 2019
Primary blast lung injury (BLI) can be defined as clinical and radiological evidence of ARDS that occurs within 12 hours of exposure to explosive blast and cannot be explained by secondary or tertiary injury ${ }^{5}$. BLI can occur independent of external trauma, chest injury and other associated injuries. It is unique to high explosive blast with effect of organs due to the overpressurization wave. The incidence of BLI has been reported to be three to four times higher in victims who are vehicle mounted or indoor as compared to outdoor blast6,7. A study by Pearce et al reported a higher incidence of blast lung injury in non-survivors of blast, 10 (3.4\%) vs 13 (10.1\%); p-value=0.006, Odds ratio $1.58(0.47-5.29)^{8}$. The modern body armor provides some protection against fragments and firearm injuries but little protection against primary blast injury ${ }^{9}$. However, the external ordinance disposal (EOD) suit can protect against the overpressure of the blast ${ }^{10}$. The patient with BLI may present with dyspnea, cyanosis, hemoptysis, hypoxemia or respiratory distress. Early diagnosis and prompt management may help prevent morbidity and mortality.

Our institutes received casualties from South and North Waziristan operational area as well as terrorist activities in civilian areas. It has a level III intensive care unit run under the supervision of a specialist intensivist. In the setting of major blast injury, the diagnosis of BLI may be over-looked resulting in delay in initiation of management. This can result in adverse 
patient outcomes including increased mortality. The purpose of our study was to ascertain the frequency of BLI and its severity, the mode of ventilatory support used for its treatment and the all-cause mortality in patient diagnosed with BLI.

\section{METHODOLOGY}

After the approval of the hospital ethics committee; this prospective, observational study was conducted at Intensive Care unit, Combined Military Hospital, Peshawar, from January 2013 to December 2014. A total of 616 patients admitted to our ICU in our prospective, observational study. Patients diagnosed with BLI were included in our study by non-probability, convenience sampling. Patients with pre-existing infection or sepsis, suspected transfusion related acute ling injury (TRALI) and non-blast explosion polytrauma induced ARDS were excluded from our study. Data was collected on a pre-designed porforma. No changes in the critical care management or investigations were made for our study. Our primary outcome was to ascertain the frequency of BLI and all cause in-hospital patient mortality. Our secondary outcome was to determine the severity of BLI, requirement of NIV, mechanical ventilation or oxygen supplementation and the association of mortality with severity of BLI.

The diagnosis of BLI was made on the basis of presence of signs and symptoms of ARDS after suffering blast injury. The partial pressure of oxygen in blood to inspired fraction of oxygen in air $(\mathrm{PaO} 2 / \mathrm{FiO} 2)$ ratio was assessed to label the severity of BLI. The severity was labelled on the basis of $\mathrm{PaO} 2 / \mathrm{FiO} 2$ ratio as mild $(200-300)$, moderate $(100-200)$ or severe $(<100)$. The patients were treated either with oxygen supplementation (mild BLI), non-invasive ventilation (moderate BLI) or mechanical ventilation with lung protec- rity of BLI and requirement of oxygen were presented as frequency and percentage. Effect modifiers like age, severity of BLI and mode of ventilation were stratified. Post stratification chi square (Fischer's exact test) were applied and $p$-value $\leq 0.05$ was taken as significant.

\section{RESULTS}

A total of 616 surgical patients were admi-tted to our Intensive care unit. 369 (59.9\%) were trauma related. Out of these, 38 ( $10.2 \%$ of trauma cases) patients were diagnosed with blast lung injury. All the patients were male with a mean age was $29.6 \pm 4.38$ years. The frequency of level of severity of BLI and measures required for management are tabulated as table-I.

We had in hospital death of two patients (5.2\%)

Table-I: Severity of blast lung injury and the management $(n=38)$.

\begin{tabular}{l|c}
\hline Variable & n (\%) \\
\hline PaO2/ FiO2 & $10(26.3)$ \\
\hline Mild & $10(26.3)$ \\
\hline Moderate & $18(47.4)$ \\
\hline Severe & $6(15.9)$ \\
\hline Ventilation management & $4(10.5)$ \\
\hline Oxygen supplementation & $28(73.6)$ \\
\hline Non-Invasive Ventilation & $2(5.2)$ \\
\hline Mechanical ventilation
\end{tabular}

with blast lung injury. The two deaths were in patients with severe BLI; who were placed on mechanical ventilation and were aged 31 and 34 years. However, there was no statistical difference inmortality in terms of age, severity of BLI or mode of ventilation ( $p$-value $>0.05$ in all groups); as tabulated as table-II.

Table-II: Effect of age, severity of BLI and Mode of ventilation on mortality.

\begin{tabular}{|c|c|c|c|c|c|}
\hline \multirow{2}{*}{\multicolumn{2}{|c|}{ Variable }} & \multicolumn{2}{|c|}{ Mortality } & \multirow{2}{*}{$p$-value } & \multirow{2}{*}{ OR } \\
\hline & & Yes & No & & \\
\hline \multirow{2}{*}{ Age (years) } & $<30$ & - & $24(66.7 \%)$ & \multirow{2}{*}{0.0 .57} & \multirow{2}{*}{1.16 (CI 0.94-1.44) } \\
\hline & $>30$ & $2(100 \%)$ & $12(33.3 \%)$ & & \\
\hline \multirow{2}{*}{ Severity } & Mild to moderate & - & $20(55.6 \%)$ & \multirow{2}{*}{0.126} & \multirow{2}{*}{1.12 (CI 0.95- 1.32) } \\
\hline & Severe & $2(100 \%)$ & $16(44.4 \%)$ & & \\
\hline \multirow{2}{*}{$\begin{array}{l}\text { Mode of } \\
\text { Ventilation }\end{array}$} & Non-invasive ventilation & - & $10(27.8 \%)$ & \multirow{2}{*}{1.00} & \multirow{2}{*}{0.92 (CI 0.83-1.02) } \\
\hline & Mechanical ventilation & $2(100 \%)$ & $26(72.2 \%)$ & & \\
\hline
\end{tabular}

tive strategy (for moderate or severe BLI).

Data was analyzed using SPSS version 20. Quantitative variables like age was presented as mean and standard deviation. T-test used to compare quantitative variable. Qualitative variables like mortality, seve-

\section{DISCUSSION}

Blast wave has been shown to have immediate as well as delayed effects on the lung. The immediate effects are: apnea (which can last from few seconds to about a minute) as well as rapid and shallow brea- 
thing ${ }^{11,12}$. BLI is postulated to be due to shearing, spalling, rupture of structures and microscopic damage to tissues as the energy in transferred at interface between tissue with different densities ${ }^{13}$. It can cause alveolar rupture leading to intrapulmonary bleeding which in turn leads to formation of free radicals. This intrapulmonary bleed also results in leukocytic accumulation and endothelial damage and edema that are characteristic pathogenesis of ARDS14,15. The V/Q mismatch and reduced surface area for gaseous exchange results in hypoxemia. The shearing blast wave can also result in pneumothorax, hemothorax, pulmonary contusions, pneumomediastinum, and subcutaneous emphysema. Blast injury can also present as bronchoalveolar or alveolo-venous fistulae. The air embolism from alveolo-venous fistulae may cause immediate or early mortality ${ }^{9}$. The clinical signs and symptoms include dyspnea, hemoptysis, cough, chest pain, hypoxemia, cyanosis, wheeze, rhonchi, crepitation and respiratory distress. BLI should be suspected in patients with a triad of dyspnea, bradycardia and hypotension with wheezing or hemoptysis following an explosion. Chest radiographs are the most common radiological tool used for diagnosis followed by computed tomography. Mackenzie et al reported diffuse loss of translucency in majority $(89.6 \%)$ of the patients. They also reported an incidence of $13.1 \%$ (14 out of 107) of blast lung injury in the patient admitted to level 4 hospital in the UK. They had a mortality of $3.7 \%{ }^{16}$. These finding correlate to our results. All of our diagnosis of BLI were based on chest radiographic findings. However, we didn't study the incidence of clinical presentation or the CT-scan as part of diagnostic tool. High resolution computed tomography (HRCT) chest was used to confirm diagnosis in equivocal cases only. Pizoret reported 15 cases of BLI in two explosions inside a bus. They reported a mortality of $33.3 \%$ in patients with BLI. This increased mortality may be due to blast injury in an enclosed space. In addition, they used $\mathrm{PaO} 2 / \mathrm{FiO} 2$ ratio of 60 as cut off for severe BLI, 60-200 for moderate BLI and $>200$ for mild BLI ${ }^{17}$. An incidence of BLI from $7-11 \%$ has been reported in survivors of explosive blasts 18,19 . Studies have shown $70-100 \%$ survival of the critically injured patients with blast lung injury without any long term pulmonary morbidity 20,21 .

We didn't report any statistically significant association of mortality from BLI with age, severity of BLI or mode of ventilation. These results do not correlate with Pizor et al who reported $75 \%$ mortality in patients with severe BLI (3 out of 4 cases); 100\% survival in moderate BLI and one mortality from traumatic brain injury with mild BLI ${ }^{17}$.

This study had certain limitations. Firstly, we did not study the associated injuries in the presence of BLI. Therefore, we can't exclude associated injuries as the cause of death. Secondly, we didn't study the long term mortality or morbidity of BLI and we cannot comment upon long term outcome after the blast lung injury.

\section{RECOMMENDATION}

Blast lung injury should be suspected in patient with respiratory distress in the setting of blast injury. Early recognition with prompt initiation of treatment and referral to a tertiary care hospital with facility of respiratory resuscitation and therapy can help improve patient outcome.

\section{CONCLUSION}

BLI was common in patients with history of survival from bomb blasts. We did not find any correlation of mortality to age, severity of BLI or mode of ventilation. As military doctors who treat both armed forces as well civilian casualties from blast injuries; the physician treating blast injury should be conscious of risk of patient developing blast lung injury; so that early recognition and prompt management with lung protective strategy can prevent increased morbidity and mortality.

\section{CONFLICT OF INTEREST}

This study has no conflict of interest to be declared by any author.

\section{REFERENCES}

1. Hannah Ritchie and Max Roser. Causes of Death. 2019 Available from: 'https://ourworldindata.org/causes-of-death

2. National Consortium for the Study of Terrorism and Responses to terrorism, Global Terrorism database. 2016 Available from: https://www.start.umd.edu/gtd/contact/

3. Stewart SK, Pearce AP, Clasper JC. Fatal head and neck injuries in military underbody blast casualties. J R Army Med Corps 2019; 165(1): 18-21.

4. Mathew ZR, Koyfman A. Blast Injuries. J Emerg Med 2015; 49(4): 573-87.

5. Scott TE, Kirkman E, Haque M, Gibb IE, Mahoney P, Hardman JG. Primary blast lung injury-a review. Br J Anaesth 2017; 118(3): 311-16.

6. Explosions and Blast Injuries: A Primer for Clinicians" (PDF). CDC. Retrieved 2013-12-29

7. Yen DD, Schecter WP. Primary blast injuries - an update concise review. World J Surg 2012; 36(5): 966-72.

8. Pearce AP, Bull AMJ, Clasper JC. Mediastinal Injury is the strongest predictor of mortality in mounted blast amongst UK deployed forces. Injury 2017; 48(9): 1900-05.

9. Smith JE. Blast Lung Injury. J Roy Nav Med Serv 2011; 97(3): 99-105. 
10. Bass CD, Davis M, Rafaels K, Rountree MS, Harris RM, Sanderson E, et al. A methodology for Assessing blast protection in explosive ordinance disposal bomb suits. Int J Occup Saf Ergon 2005; 11(4): 347-61.

11. Sawdon M, Ohnishi M, Watkins PE, Kirkman E. The effects of primary thoracic blast injury and morphine on the response to haemorrhage in the anaesthetised rat. Exp Physiol 2002; 87(6): 683-89.

12. Jaffin JH, McKinney L, Kinney RC, Cunningham JA, Moritz DM, Kraimer JM, et al. A laboratory model for studying blast overpressure injury. J Trauma 1987; 27(4): 349-56.

13. Sreekanth C, Bai R. Blast lung injury: our experience. Hong Kong J Emerg Med 2017; 24(2): 85-89.

14. Gorbunov NV, McFaul SJ, Januszkiewicz A, Atkins JL. Pro-inflammatory alterations and status of blood plasma iron in a model of blast-induced lung trauma. Int J Immunopathol Pharmacol 2005; 18(3): 547-56.

15. Chavko M, Adeeb S, Ahlers ST, McCarron RM. Attenuation of pulmonary inflammation after exposure to blast overpressure by $\mathrm{N}$-acetylcysteine amide. Shock 2009; 32(3): 325-31.

16. MacKenzie Iain MJ, Tunnicliffe B. Blast injuries to lung; epidemiology and management. Philos Trans R Soc Lond B Biol Sci 2011; 366(1562): 295-99.

17. Pizor R, Oppenhein-Eden A, Matot I, Weiss YG, Eidelman LA, Rivkind $\mathrm{Al}$, et al. Blast lung injury from an explosion on a civilian bus. Chest 1999; 115(1): 165-71.

18. Aboudara M, Mahoney PF, Hicks B, Cuadrado D. Primary blast lung injury at a NATO Role 3 hospital. J R Army Med Corps 2014; 160(2): 161-66.

19. Johnston AM, Bllard M. Primary blast lung Injury. Am J Respir Crit Care Med 2015; 191(12): 1462-63.

20. Lemonick DM. Bombing and blast injuries: A Primer for physicians. Am. J Clin Med Res 2011; 8(3): 134-40.

21. Hirshberg B, Oppenhein-Eden A, Pizov R, Sklair-Levi M, Rivkin A, Bardach E, et al. Recovery from Blast lung injury: one year follow-up. Chest 1999; 116(6): 1683-88. 